\title{
Honokiol and Magnolol Induce Apoptosis and Cell Cycle Arrest in Human Ovarian Cancer Cells
}

\author{
Worawat Songjang ${ }^{1}$ and Arunya Jiraviriyakul ${ }^{2 *}$
}

\section{Worawat Songjang ${ }^{1}$ and Arunya Jiraviriyakul ${ }^{2 *}$}

'Biomedical Science Graduated School, Faculty of Allied Health Sciences, Naresuan University, Phitsanulok 65000, THAILAND. ${ }^{2}$ Department of Medical technology, Faculty of Allied Health Sciences, Naresuan University, Phitsanulok 65000, THAILAND.

\section{Correspondence}

\section{Arunya Jiraviriyakul}

Department of Medical technology, Faculty of Allied Health Sciences, Naresuan University, Phitsanulok 65000, THAILAND.

Phone no: +6655966389;

Fax; +6655966234;

E-mail: arunyaj@nu.ac.th

History

- Submission Date: 22-05-2019;

- Review completed: 25-06-2019;

- Accepted Date: 25-06-2019.

\section{DOI : 10.5530/pj.2019.11.174}

Article Available online

http://www.phcogj.com/v11/i5

\section{Copyright}

(C) 2019 Phcogj.Com. This is an openaccess article distributed under the terms of the Creative Commons Attribution 4.0 International license.

\begin{abstract}
Introduction: Ovarian cancer is a major cause of cancer-related death among women. The growth, persistence, and cancer metastasis are causes of poor prognosis and high mortality rate. Honokiol and magnolol are derivative compounds extracted from the root and stem bark of Magnolia officinalis. Many studies have reported that honokiol and magnolol have anti-tumour effects on various types of cancer. The present study investigates the anti-tumour effect of these compounds on human ovarian cancer. Methods: Ovarian cancer cell lines, SKOV3 and ES-2 cells were tested with honokiol and magnolol to determine their responses including the cytotoxicity, cell proliferation, induction of cell apoptosis and metastasis ability. Result: The results indicate that low concentrations of honokiol and magnolol suppressed the proliferation of ovarian cancer cells through induction of cell cycle arrest at G0/G1 and down-regulation of the cyclin D1 protein. These compounds also exhibited an anti-metastatic ability mediated by inhibiting migration, adhesion, and MMP activities. Additionally, high concentrations of honokiol and magnolol could activate cell death associated with the apoptosis signalling pathway, either along an intrinsic or extrinsic pathway. Conclusions: The data provides evidence that honokiol and magnolol have potential anti-tumour properties and minimal toxicity on normal cells, and could therefore be applied in the treatment of ovarian cancer.
\end{abstract}

Key Words: Honokiol, Magnolol, Ovarian Cancer, Proliferation, Apoptosis, Metastasis.

\section{INTRODUCTION}

Epithelial ovarian cancer is the fourth most common cause of cancer-related death among women worldwide. Over 220,000 woman are diagnosed with epithelial ovarian cancer every year, with the incidence of the disease estimated to be 5 per 100,000 people. $^{1}$ According to asymptomatic in early stage disease, over $80 \%$ of patients have symptoms even when the disease is widely metastatic to abdominal lumen. ${ }^{2}$ The overall survival rate of patients with ovarian cancer has improved from $36 \%$ to $46 \%$ due to taxane and platinum chemotherapies. ${ }^{3}$ Yet chemotherapeutic agents can cause side effects and are only able to prolong five-year survival rates for patients with an advanced stage of the disease-such as stage IIICfor a mere $39 \%$ of patients. ${ }^{4} \mathrm{New}$ effective treatment is therefore crucial to improve survivability and should be subject to intensive study.

Honokiol (5,3'-Diallyl-2,4'-dihydroxybiphenyl) and magnolol (5,5'-Diallyl-2,2'-biphenyldiol) are bioactive herbal-derived compounds which are extracted from the bark, seed cones, and leaves of Magnolia officinalis. The pharmacological effect of these compounds have been demonstrated to include anti-stress, anti-depressant, antiinflammatory, hepatoprotective, and anti-cancer effects. ${ }^{5}$ The anti-cancer properties of magnolia have recently been reported to be associated with inhibiting cancer cell proliferation and induction of cancer cell death by apoptosis in several cancer cell lines, including colon cancer, ${ }^{6}$ hepatocellular carcinoma, ${ }^{7}$ leukaemia, ${ }^{8}$ lung cancer, ${ }^{9}$ and ovarian cancer. ${ }^{10}$ Previous studies have indicated that both honokiol and magnolol proficiently inhibit cancer cell proliferation by blocking DNA synthesis and that they also induce cancer cell apoptosis. ${ }^{11}$ Interestingly, Chuang and Hsu reported that honokiol affects the ovarian cancer cell line by down-regulating the expression of HER2 gene and inhibiting the metastatic potential of SKOV $3 .{ }^{10}$ Moreover, Zhengyu $\mathrm{Li}$ and Liu demonstrated that honokiol induces ovarian cancer cell line apoptosis and inhibits cancer angiogenesis in animal models. ${ }^{12}$ But the mechanisms of honokiol and magnolia in relation to ovarian cancer remain unclear.

There present study therefore aimed to investigate the cytotoxicity effect of honokiol and magnolol on human monocyte-derived macrophage, as well as the underlying mechanisms on the ovarian cancer cell line, including for SKOV3 and ES- 2 cells. The researcher's demonstrate that these compounds inhibited cell proliferation and also suppressed the metastasis ability of the cancer cells. Notably, the cytotoxicity of these compounds on human macrophages is lower than ovarian cancer cell lines. Moreover, honokiol and magnolol induced ovarian cancer cell apoptosis, either along a mitochondriadependent or an independent pathway. The data concurs with the previous evidence which finds that honokiol and magnolol are potential therapeutic agents for the treatment of ovarian cancer.

\section{MATERIAL AND METHODS}

\section{Cell culture}

Poorly differentiated ovarian clear cell carcinoma and adenocarcinoma cell lines, ES-2 and SKOV3 were kindly provided from Prof. Seiji Okada, Centre for AIDS Research Kumamoto University, Japan. Cell lines were maintained in Dulbecco's modified 
Eagle's medium (DMEM) at $37^{\circ} \mathrm{C}$ humidified atmosphere with $5 \% \mathrm{CO}_{2}$, supplemented with $5 \%$ fetal bovine serum, 100 units $/ \mathrm{mL}$ of penicillin, $100 \mu \mathrm{g} / \mathrm{mL}$ of streptomycin, and $0.25 \mu \mathrm{g} / \mathrm{mL}$ of amphotericin B.

\section{Generation of human monocyte-derived macrophages}

Peripheral leukocyte-rich buffy coats from healthy volunteers were collected at blood bank unit of Naresuan University hospital under the approval of Naresuan University Institutional review board IRB No. 0846/60. Monocytes were isolated following standard protocol. Briefly, the PBMC was first isolated by using Ficoll-Hypaque (GE Healthcare, Freiburg, Germany) gradient centrifugation. Then, PBMC was performed Percolll (GE Healthcare, Freiburg, Germany) gradient centrifugation for monocyte enrichment. The monocyte fraction was subsequently resuspended in RPMI1640 5\% FBS and plated in cell culture flask for allowing to adhere for $2 \mathrm{~h}$. The non-adherence cell was removed by washing with PBS for 3 times. The adherence monocyte was derived to macrophage by continually culture in RPMI1640 10\% FBS supplemented with $50 \mathrm{ng} / \mathrm{mL}$ of human recombinant GranulocyteMacrophage Colony-Stimulating Factor (rhGM-CSF) (Miltenyi Biotec, Bergisch Gladbach, Germany). The medium was changed by replacing with fresh medium for every 3 days.

\section{Cell cytotoxicity}

The cell cytotoxicity was carried out by MTT assay. Briefly, human macrophage and ovarian cell lines were seed at density $5 \times 10^{3}$ cells per well in 96-well plate. After cell adhesion, honokiol and magnolol (Sigma-Aldrich, MO, USA) were added in different concentration and incubated at $37^{\circ} \mathrm{C}$ humidified atmosphere with $5 \% \mathrm{CO}_{2}$ for 24,48 and 72 h. Subsequently, $0.5 \mathrm{mg} / \mathrm{mL}$ of MTT reagent was added and incubated for another $4 \mathrm{~h}$. The formazan product was dissolved by DMSO before measuring light absorbent by microplate spectrophotometer at $540 \mathrm{~nm}$. The $\%$ cell viability was calculated following the formula ((honokiol or magnolol treated $\left.\mathrm{Abs}_{540}\right) /\left(\right.$ control $\left.\left.\mathrm{Abs}_{540}\right)\right) \times 100(\%)$.

\section{Cell cycle analysis}

Cell cycle analysis was performed utilizing Muse $\mathrm{e}^{\mathrm{ma}}$ Cell Analyzer from Millipore (Billerica, MA) following manufacturer's instruction. Briefly, ovarian cancer cell lines were incubated with different concentration of honokiol for $24 \mathrm{~h}$ before washing with PBS and fixing with $70 \%$ ethanol for another $3 \mathrm{~h}$. Then, cells were stained with propidium iodide (PI) and processed for cell cycle analysis.

\section{Apoptosis analysis}

Annexin V \& Dead Cell and Caspase 3/7 expression assay were carried out utilizing Muse ${ }^{\mathrm{ix}}$ Cell Analyzer from Millipore (Billerica, MA) following manufacturer's instruction. Briefly, SKOV3 and ES-2 were treated with varies concentration of honokiol for $24 \mathrm{~h}$. Treated cell were subsequently incubated with Annexin V and Dead Cell Reagent (7AAD), and Muse ${ }^{\mathrm{mt}}$ Caspase-3/7 reagent before analyzing for Annexin V/PI staining and Caspase 3/7 expression. The results were representing by event of live cell, apoptotic cell and dead cell.

\section{Western blot analysis}

After incubating ovarian cancer cell lines with indicated treatment, treated cell were washed with ice-cold PBS before suspending cell pellet with RIPA lysis buffer plus protease inhibitor cocktail. Then, protein lysate was collected by centrifugation and measured protein concentration using Bradford assay. The protein was then separated by SDS-PAGE and transferred onto PVDF membranes. After that, membranes were blocked the non-specific binding by $5 \%$ skim milk buffer for $1 \mathrm{~h}$ before washing with TBST buffer. The membranes were then incubated with each primary antibody, anti-caspase 3, anti-caspase 8 , anti-caspase 9 and anti-cyclin D1 (antibodies were purchased from
Cell Signaling (MA, USA)) with gentle shaking at $4^{\circ} \mathrm{C}$ overnight. Then, membranes were washed with TBST and incubated with HRP-linked anti-rabbit antibody for $1 \mathrm{~h}$ at room temperature and washed again before incubating with detection reagent. The image was developed by Chimidoc ${ }^{\mathrm{Tw}}$ XRS and analyzed by Image Lab (Bio-rad ${ }^{\star}$ ).

\section{Cell adhesion assay}

Ovarian cancer cell lines were seed at density $2 \times 10^{4}$ cells and pretreated with honokiol for 30 minutes. The treated cells were then seeded onto 96-well plate precoated with Matrigel, incubated for 40 minutes at $37^{\circ} \mathrm{C}$ humidified atmosphere with $5 \% \mathrm{CO}_{2}$. The unattracted cells were removed by washing with PBS for 3 times before staining with $0.5 \%$ crystal violet in $20 \%$ methanol for 30 minutes. Attracted cells were randomly photographed under microscopy at 10X objective. After that, crystal violet was eluted by $70 \%$ ethanol and measured light absorbent by microplate spectrophotometer at $570 \mathrm{~nm}$. The $\%$ cell adhesion was calculated following the formula ((honokiol treated $\left.\mathrm{Abs}_{570}\right) /($ control $\left.\left.\mathrm{Abs}_{570}\right)\right) \times 100(\%)$.

\section{Cell scratch assay}

SKOV3 and ES-2 were seeded onto 6-well plate and cultured at $37^{\circ} \mathrm{C}$ humidified atmosphere with $5 \% \mathrm{CO}_{2}$ until $90-100 \%$ confluent. Then, cells were scratched by using $200 \mu \mathrm{L}$ pipette tip before washing with PBS. Culture medium was replaced by complete medium containing honokiol. The scratching wound was monitoring photographed under microscope at 10X objective for every $6 \mathrm{~h}$. Scratching wound area was measured using ImageJ program and calculated \% migration following equation $(($ area at $0 \mathrm{~h}-$ area at $\mathrm{xh}) /($ area at $0 \mathrm{~h}) \times 100(\%)$.

\section{Gelatine zymography}

Ovarian cancer cell lines were seeded onto cell culture dish and incubated at $37^{\circ} \mathrm{C}$ humidified atmosphere with $5 \% \mathrm{CO}_{2}$ until $80 \%$ confluent. Cell culture media was removed and washed with PBS for 3 times before replacing with serum-free medium containing honokiol in different concentration for $24 \mathrm{~h}$. The conditioned medium was collected and concentrated using Amicon ${ }^{\bullet}$ Ultra-2 Centrifugal Filter units (Millipore MA, USA) following manufacturer's instruction for 10x final concentration. The conditioned medium was then mixed with sample loading buffer before subjecting to $10 \%$ SDS-PAGE containing $1 \%$ gelatine. Then, the gel was washed with washing buffer $(\mathrm{pH} 7.5$, $2.5 \%$ Triton X-100) for 30 minutes, and incubated in developing buffer ( $\mathrm{pH} 7.5,1 \%$ Triton $\mathrm{X}-100,50 \mathrm{mM}$ Tri-HCl, $5 \mathrm{mM} \mathrm{CaCl}_{2}$ and $1 \mu \mathrm{M}$ $\mathrm{ZnCl}_{2}$ ) overnight at $37^{\circ} \mathrm{C}$. Gel was then stained with $0.5 \%$ Coomassie blue R-250 in 45\% methanol, 10\% acetic acid, and destained with $45 \%$ methanol, 10\% acetic acid until clear bands. The gelatinolytic activity of MMPs was visualized by gel photographed using Chimidoc ${ }^{\mathrm{Tx}}$ XRS $\left(\right.$ Bio-rad $\left.^{\circledR}\right)$.

\section{Statistical analysis}

All values were represented as Mean \pm SD. The comparisons between group was accessed significance using Student t-test, one-way or twoway analysis of variances (ANOVA), follow when appropriate by the Tukey-Kramer and Dunnett test. The statistical testing was performed using commercially available software GraphPad Prism version 7. At $\rho$-value less than 0.05 will be considered as statistically significant.

\section{RESULTS}

\section{The cytotoxicity of honokiol and magnolol}

The cytotoxicity of honokiol and magnolol on ovarian cancer cell lines, SKOV3 and ES-2, was determined. The results indicate that these compounds significantly suppressed the viability of SKOV3 and ES-2 in dose and time-dependent manners (Figure 1). The IC50 of honokiol 
with SHOV3 at $24 \mathrm{~h}, 48 \mathrm{~h}$, and $72 \mathrm{~h}$ were $58.31,36.72$, and $28.4 \mu \mathrm{M}$, and with ES2 were 45.41, 28.32, and $28.69 \mu \mathrm{M}$, respectively. Meanwhile, the IC50 of magnolol with SKOV3 at $24 \mathrm{~h}, 48 \mathrm{~h}$, and $72 \mathrm{~h}$ were 100 , 98.11, and $67.61 \mu \mathrm{M}$, while with ES-2 they were 94.57, 64.7, and 34.18 $\mu \mathrm{M}$, respectively (Table 1 ). The cytotoxicity of these compounds on the human monocyte-derived macrophage was also studied. These results show that honokiol and magnolol exhibited less cytotoxicity on normal cells compared to cancer cells (Figure 2), as indicated by the IC50 of honokiol on human macrophage at $24 \mathrm{~h}, 48 \mathrm{~h}$, and $72 \mathrm{~h}$ at $79,64.3$, and $49.1 \mu \mathrm{M}$, respectively (Table 1). The data suggests that both honokiol and magnolol significantly induced ovarian cancer cell death while exhibiting minimal cytotoxicity on normal cells.

Honokiol and magnolol suppress ovarian cancer cell proliferation

To study the mechanism of these compounds on human ovarian cancer, honokiol was used to represent magnolia-derivative compounds. To study its anti-proliferative effect, SKOV3 and ES-2 were incubated with these compounds and cell cycle analysis was performed. The results show that at the sub IC50 concentration of honokiol significantly increased cell population at the G0/G1 phase, and it also significantly decreased cell population at the $\mathrm{S}$ and $\mathrm{G} 2 / \mathrm{M}$ phases in a dose-dependent manner (Figures 3A-B). Indicated that honokiol was the cause of cell cycle arrest at the G0/G1 phase. Moreover, the same concentrations of honokiol markedly decreased the expression of cyclin D1 in a dose-dependent manner (Figure 3C). These results suggest that honokiol suppressed ovarian cancer cells proliferation mediated by cyclin D1 degradation and were the cause of cell cycle arrest.

Honokiol and magnolol induce ovarian cancer cell apoptosis

The researchers next determined whether honokiol induced human ovarian cell death through an apoptosis mechanism. Ovarian cancer

A

SKOV3

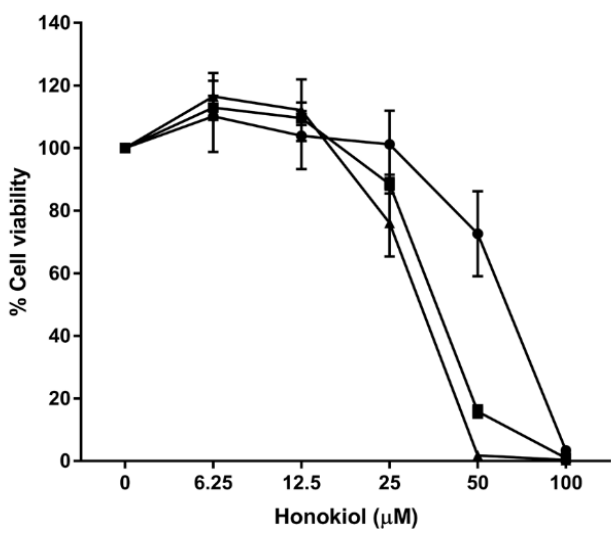

B

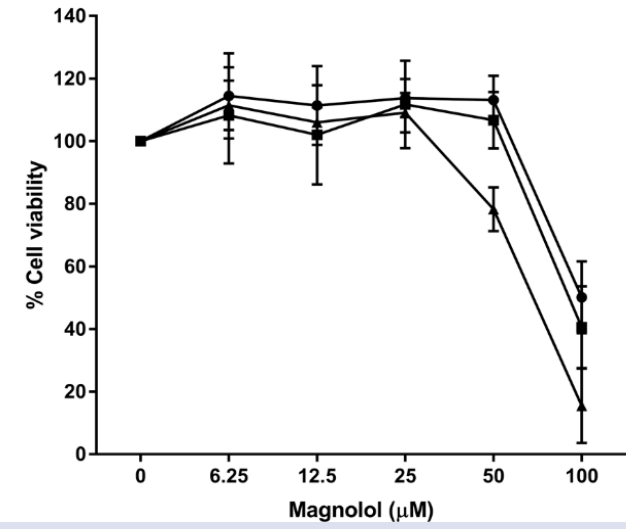

ES-2
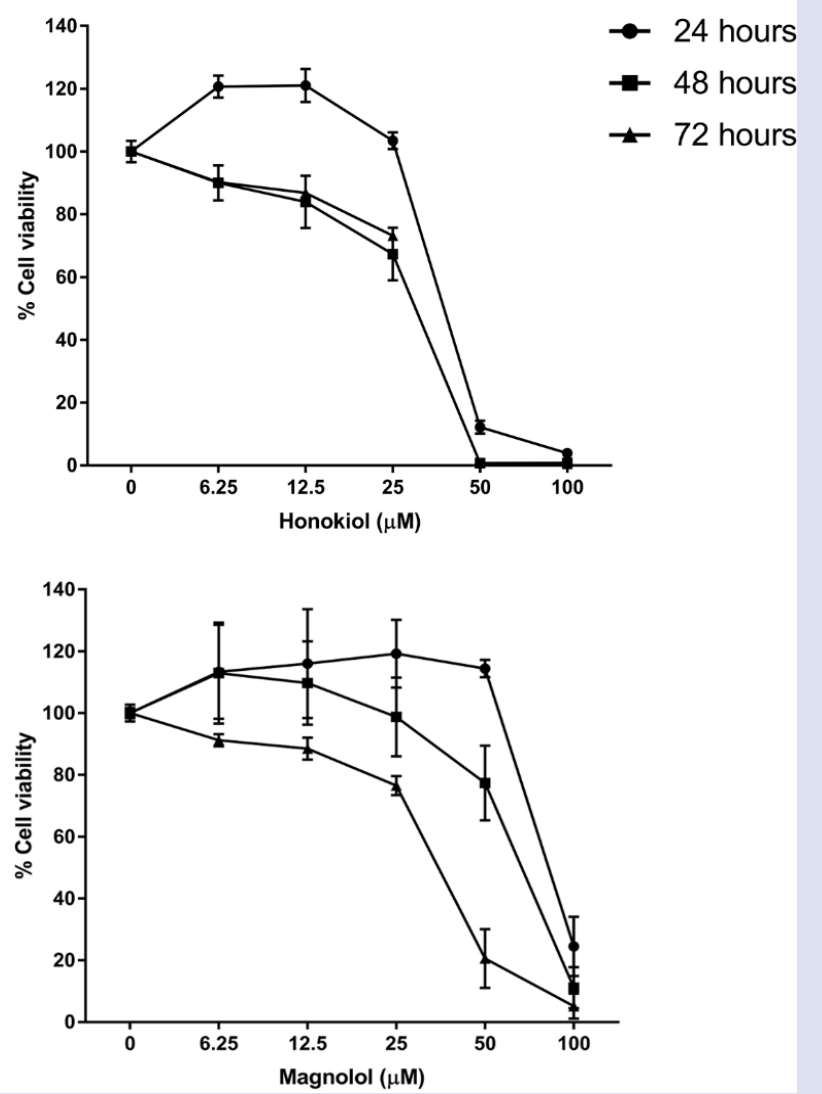

Figure 1: The cytotoxicity effect of honokiol and magnolol on ovarian cancer cells. SKOV3 and ES-2 cells were treated with (A) honokiol and (B) magnolol following indicated concentration, after 24,48 and $72 \mathrm{~h}$, cell viability was determined using MTT assay. Cells were treated with DMSO and ethanol as negative control, and all groups were normalized with control group. The results represented as mean \pm SD from three independent experiments.

Table 1: $\mathrm{IC}_{50}$ of honokiol and magnolol on ovarian cancer cells and human macrophages.

\begin{tabular}{|c|c|c|c|c|c|c|}
\hline \multirow{2}{*}{ Cell lines } & \multicolumn{3}{|c|}{ Honokiol $(\mu \mathrm{M})$} & \multicolumn{3}{|c|}{ Magnolol $(\mu \mathrm{M})$} \\
\hline & 24 hours & 48 hours & 72 hours & 24 hours & 48 hours & 72 hours \\
\hline SKOV3 & 58.31 & 36.72 & 28.4 & 100 & 98.11 & 67.61 \\
\hline ES-2 & 45.41 & 28.32 & 28.69 & 94.57 & 64.7 & 34.18 \\
\hline Macrophages & 79.00 & 64.30 & 49.10 & N/A & N/A & N/A \\
\hline
\end{tabular}

Cells were treated with honokiol and magnolol for 24 and $48 \mathrm{~h}$, cell viability was carried out by MTT assay, and the $\mathrm{IC}_{50}$ was calculated using GraphPad Prism version 7. The IC50 of magnolol on macrophages could not calculated according to the compound that not dramatically toxic on cells. 


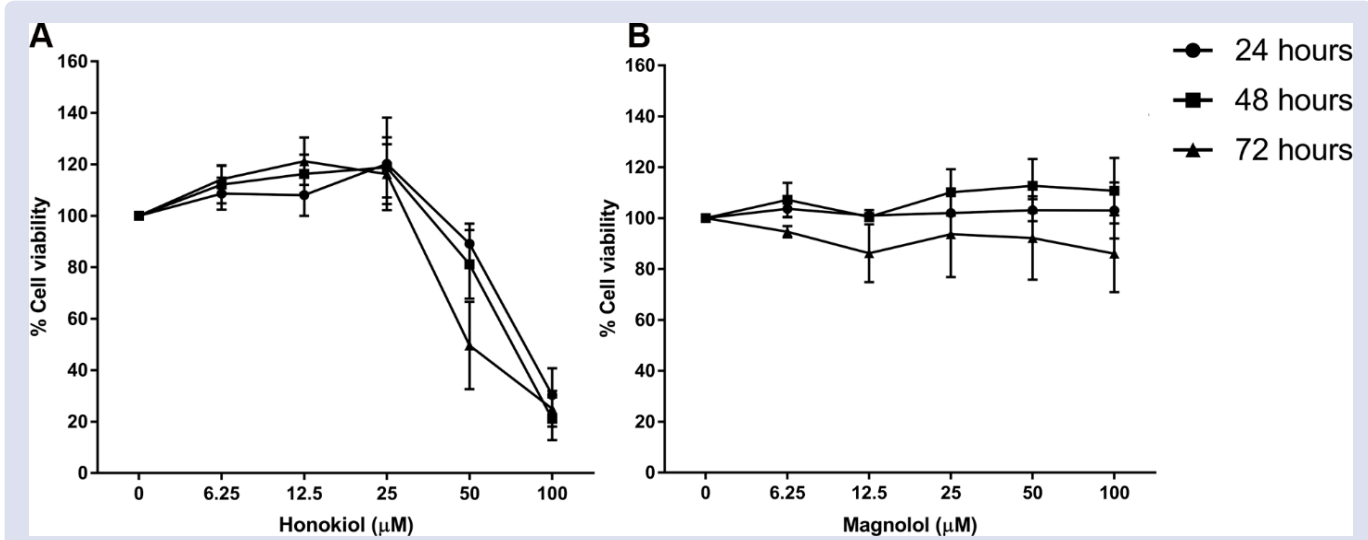

Figure 2: The cytotoxicity effect of honokiol and magnolol on human macrophage. Human monocyte derivedmacrophage was treated with (A) honokiol and (B) magnolol following indicated concentration, after 24, 48 and $72 \mathrm{~h}$, cell viability was determined using MTT assay. Cells were treated with DMSO and ethanol as negative control, and all groups were normalized with control group. The results represented as mean \pm SD from three independent experiments.

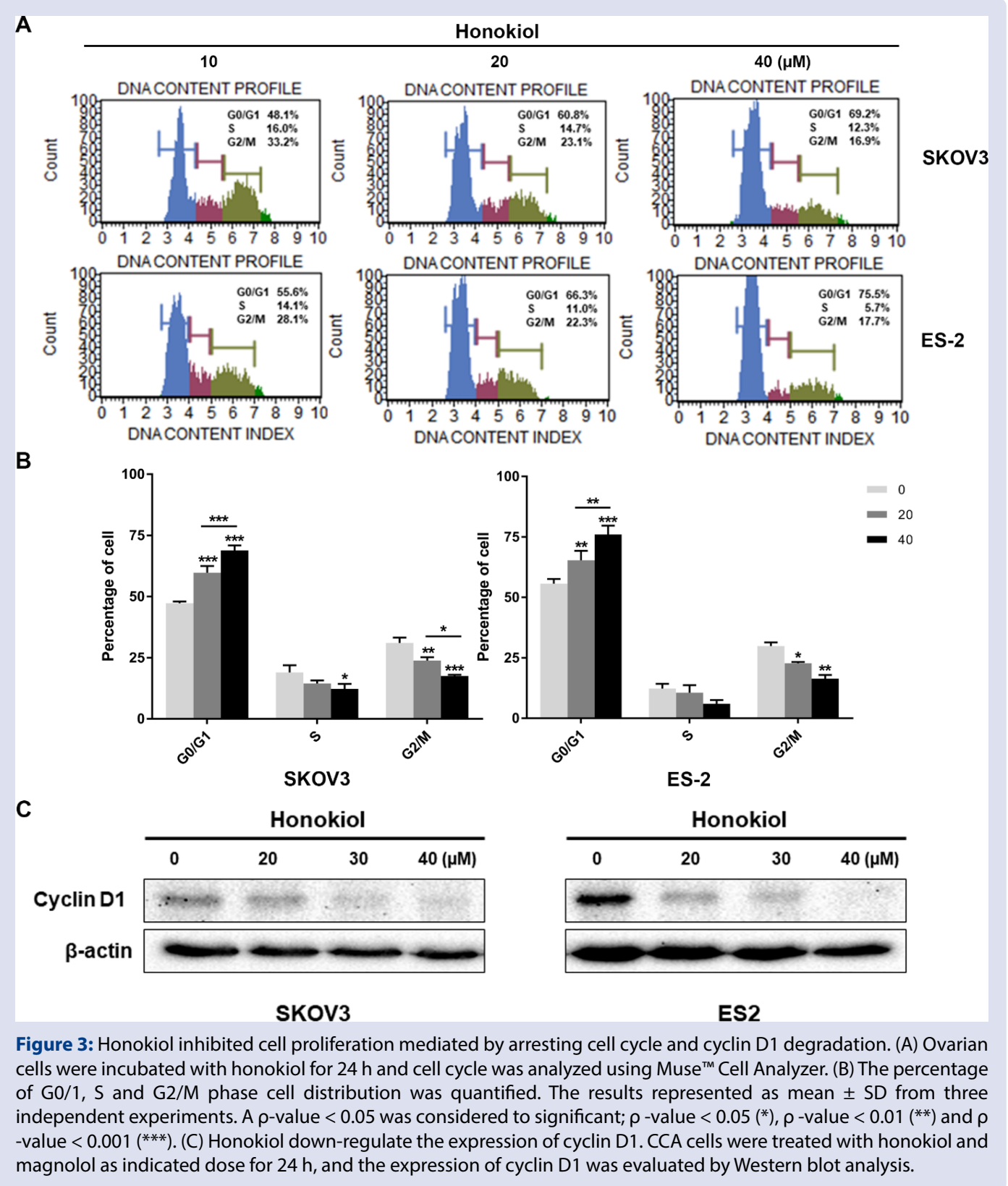


cells were incubated with honokiol and Annexin V-PI staining was then performed used to evaluate the PS externalisation, which is the apoptosis hallmark. The results show that honokiol significant induced cell apoptosis in both the early and late phases in a dose-dependent manner (Figures 4A-B). Moreover, induction of cell apoptosis was proved by caspase-3/-7 activation testing, which is the executioner enzyme for apoptosis induction. Consistent with the Annexin V-PI assay, honokiol significantly increased the activity of caspase- $3 /-7$ in a dose-dependent manner when compared with the control counterpart (Figures 4C-D).
Additionally, the apoptosis induction method caused by honokiol was further elucidated. SKOV3 cells were incubated with the honokiol compound and the expression of caspase-3, - 8 and -9 was determined using Western blot analysis. The honokiol treatment with SKOV3 resulted in time-dependent increases of cleaved caspase-3 (17 and $19 \mathrm{kDa}$ ), beginning at $4 \mathrm{~h}$ (Figure 5). Additionally, honokiol increased the cleaving of procaspase-8 $(57 \mathrm{kDa})$ to a 10 activated form $(10 \mathrm{kDa})$, and it also induced the proteolytic activity of procaspase-9 $(47 \mathrm{kDa})$ to cleaved caspase-9 $(35$ and $37 \mathrm{kDa}$ ) (Figure $5)$. These results suggest that honokiol may have activated ovarian

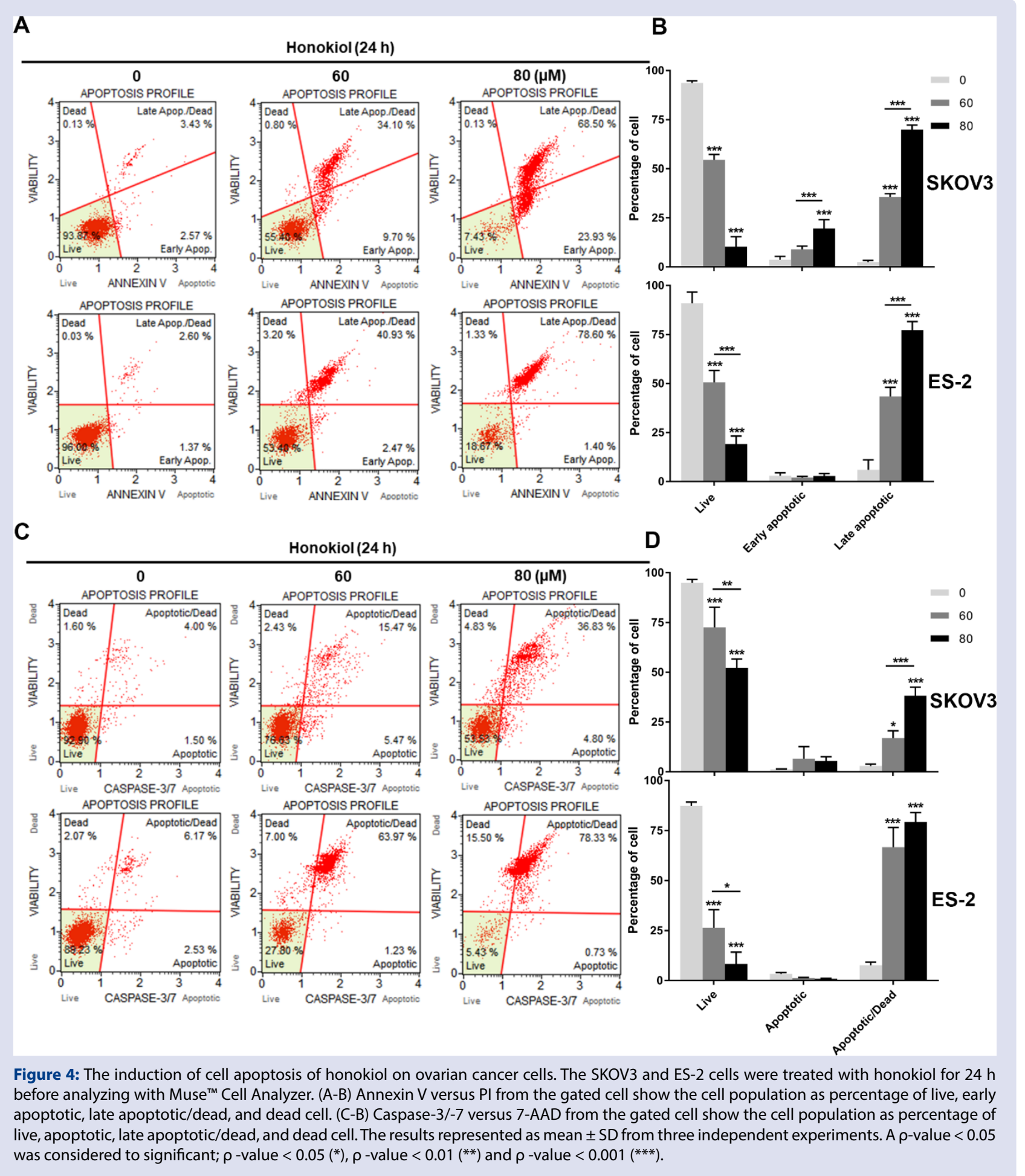




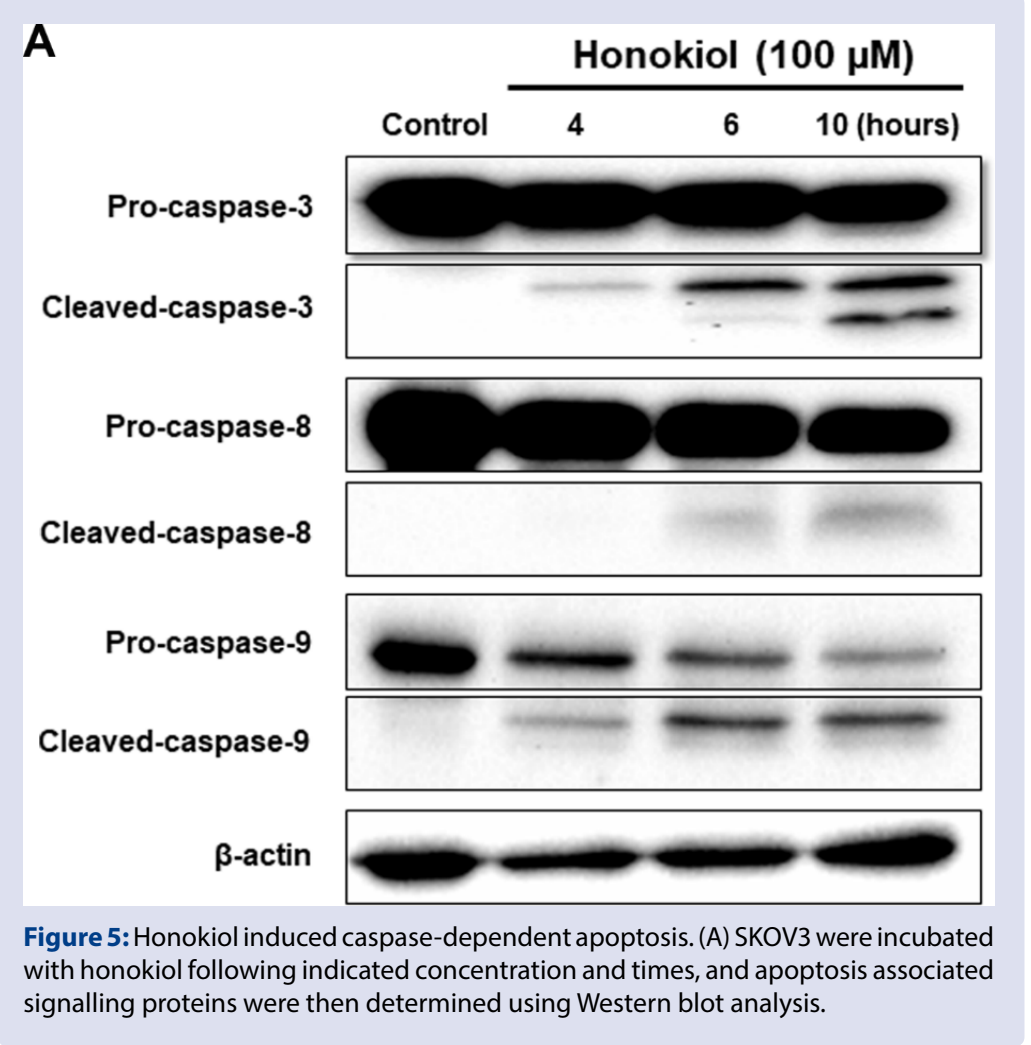

cancer cell apoptosis through the caspase-dependent pathway, which is either a mitochondria-dependent or a mitochondria-independent pathway.

\section{Honokiol and magnolol suppress ovarian cancer cell metastasis}

The anti-metastatic ability of honokiol on ovarian cancer cells was then studied. The adhesion assay was performed in both the SKOV3 and ES-2 cells using a cell culture plate precoating with Matrigel. As shown in Figure 6, honokiol concentrations of 15-60 $\mu \mathrm{M}$ significantly suppressed the adherence ability of SKOV3 and ES-2 in a dosedependent manner. To further explore the effect of the compound on migration, ovarian cells were treated with honokiol at $15-30 \mu \mathrm{M}$ and the migration ability was determined using cell scratch assay. The results find that honokiol significantly suppressed the migration of SKOV3 and ES-2 in time and dose-dependent manners (Figure 7A-B). Finally, the proteolytic enzymes-MMP -2-which contributes to cancer cell invasion and metastasis was measured using gelatin zymography. Gelatin zymography was performed using a conditioned medium from honokiol-treated SKOV3 and ES-2 cells. As shown in Figure 7C, honokiol clearly suppressed the activity of MMP-2 in both SKOV3 and ES-2 in a dose-dependent manner. Combined, these results suggest that honokiol potentially suppresses the metastatic ability of human ovarian cancer cells.

\section{DISCUSSION}

While ovarian cancer is the seventh most commonly diagnosed cancer among women worldwide, it is the fourth most common cause of cancer-related deaths among women, accounting for 152,000 annual deaths around the world. ${ }^{13}$ Patients with advanced metastasis cancer are typically managed using cytoreductive surgery and perioperative platinum-based chemotherapy. Although this paradigm may improve rates of survival, over $75 \%$ of ovarian cancer patients will eventually experience tumour recurrence. ${ }^{14}$ Due to the high relapse rate and poor prognosis, interest is increasing in the drug screening of new therapeutic agents in the treatment of ovarian cancer. The present study demonstrates that two magnolia derived compounds, honokiol and magnolol, are potential therapeutic agents for the treatment of ovarian cancer.

Honokiol and magnolol's selective action is particular fascinating, as reflected by the IC50 of the compounds which have shown high toxicity for cancer cells, while having minimal toxicity for human macrophages. For the first time, the present study has demonstrated the cytotoxicity of honokiol and magnolol on normal human cells, with the results subsequently supporting the use of these compounds as therapeutic agents in the treatment of ovarian cancer. This finding is in accordance with previous reports which show that honokiol exhibits a stronger cytotoxicity than magnolol on various types of cancer, such as squamous lung carcinoma ${ }^{9,15}$ and ovarian cancer. ${ }^{10,16}$ This effect may be described by the different isomer structure of honokiol compared to magnolol due to the position of the hydroxyl group that provides distinct properties, such as its solubility and binding pocket on target. Interestingly, low concentrations of these compounds inhibit cell proliferation via arresting the cell cycle progression at the G0/G1 phase. Moreover, the researchers also examined the expression of cyclin D1, which is a cell cycle regulator protein that plays a role in initiating cell cycle progression. The data suggests that honokiol and magnolol inhibited ovarian cancer cells proliferation, which was mediated by induction of cell cycle arrest and cyclin D1 degradation. This is similar to a previous study which found that magnolol treatment on SKOV3 caused cell arrest at G0/G1 and down-regulation of cyclin D1. ${ }^{10}$

It has been reported that honokiol and magnolol could induce cancer cell death mediated by many mechanisms, including autophagy and apoptosis. ${ }^{11,17}$ A previous study has demonstrated that honokiol can stimulate cell apoptosis mediated by reactive oxygen species production, DNA damage, and up-regulation of proapoptotic proteins that 


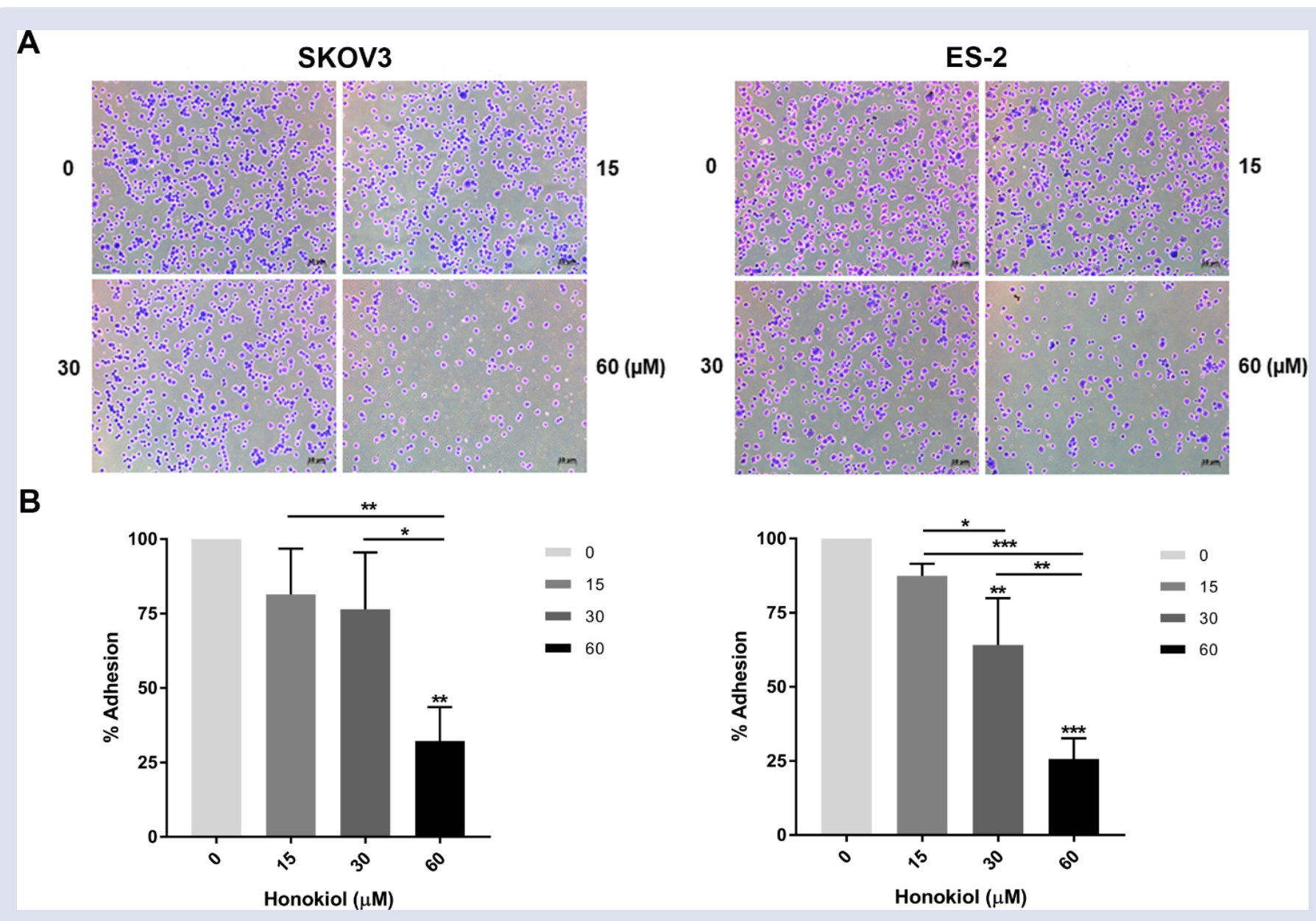

Figure 6: Honokiol inhibited cell adhesion of ovarian cancer cells. (A) Honokiol pretreated SKOV3 and ES-2 were allowed to attach on Matrigel-coated plate for indicating times. The unbound cells were wash out and remained cell were photographed $(\times 100)$ after crystal violet staining. (B) Cell number was quantified by measuring light absorbent at $570 \mathrm{~nm}$ before calculating to \%adhesion by normalized with control group. The results represented as mean \pm SD from three independent experiments. A $\rho$-value $<0.05$ was considered to significant; $\rho$-value $<0.05(*), \rho$-value $<0.01\left(^{* *}\right)$ and $\rho$-value $<0.001\left({ }^{* * *}\right)$.

consequently act directly on the mitochondrial membrane, resulting in the release of cytochrome $\mathrm{C}$ and the activation of caspase- 9 and caspase- $3 .{ }^{17}$ Meanwhile, these compounds can cooperate with Fas and TRAI ligands to enhance apoptosis mediated caspase- 8 and caspase- 3 , respectively. ${ }^{17}$ The present study demonstrated that these compounds induced ovarian cancer cell apoptosis, as reflected by the increased PS externalisation and up-regulation of execution caspase- 3 enzyme, both in terms of their activity and expression level. Moreover, they also upregulated the expression of caspase- 8 and -9 , suggesting that honokiol and magnolol could activate ovarian cancer cell apoptosis mediated by either mitochondria-dependent or independent pathways.

Cancer metastasis is the major cause of cancer morbidity and mortality for all types of cancer. Metastasis involves multiple sequential and interrelated steps, including detachment, migration, invasion, and adhesion. ${ }^{18}$ The present study shows that honokiol inhibits the migration and adhesion of SKOV3 and ES-2 cells. Additionally, honokiol also has an inhibitory effect on MMP-2 activity, which contributes to extracellular degradation and cancer invasion and metastasis. These results support the existing evidence which suggests that honokiol inhibits the adhesion activities of the glioblastoma cell line by regulating adhesion molecules such as ICAM-1 and VCAM$1 .^{19}$ Moreover, magnolol suppressed the migration and invasion abilities of breast cancer and non-Opisthorchis viverrini-associated
CCA cell lines which was mediated by inhibiting the NF- $\kappa B$ signalling pathway and MMP activities. ${ }^{20,21}$ Therefore, the evidence indicates that honokiol also acts as an anti-metastatic agent for ovarian cancer cells.

\section{CONCLUSION}

The present study demonstrates the anti-tumour activities of honokiol and magnolol on ovarian cancer cells. These magnolia-derived compounds exhibited antiproliferation effects, mediated by cell cycle arrest and cyclin D1 degradation. Notably, these compounds had a minimal toxicity on human macrophage. In addition to inducing apoptosis through either intrinsic or extrinsic mechanisms, honokiol and magnolol also inhibited metastasis abilities by inhibiting the cancer cell's adhesion, migration, and MMP-2 activities. The researchers subsequently propose that honokiol and magnolol are potential suitable therapeutic agents for alternative ovarian cancer treatment.

\section{ACKNOWLEDGEMENT}

This study was financially supported by Naresuan University Research endowment fund (Grant I.D. R2557B036). We are grateful to Prof. Seiji Okada, Centre for AIDS Research Kumamoto University, Japan, for kindly provided the ovarian cancer cell lines that use in this study. We would like to thank ProofRead4Sure service for English proof reading and editing. 


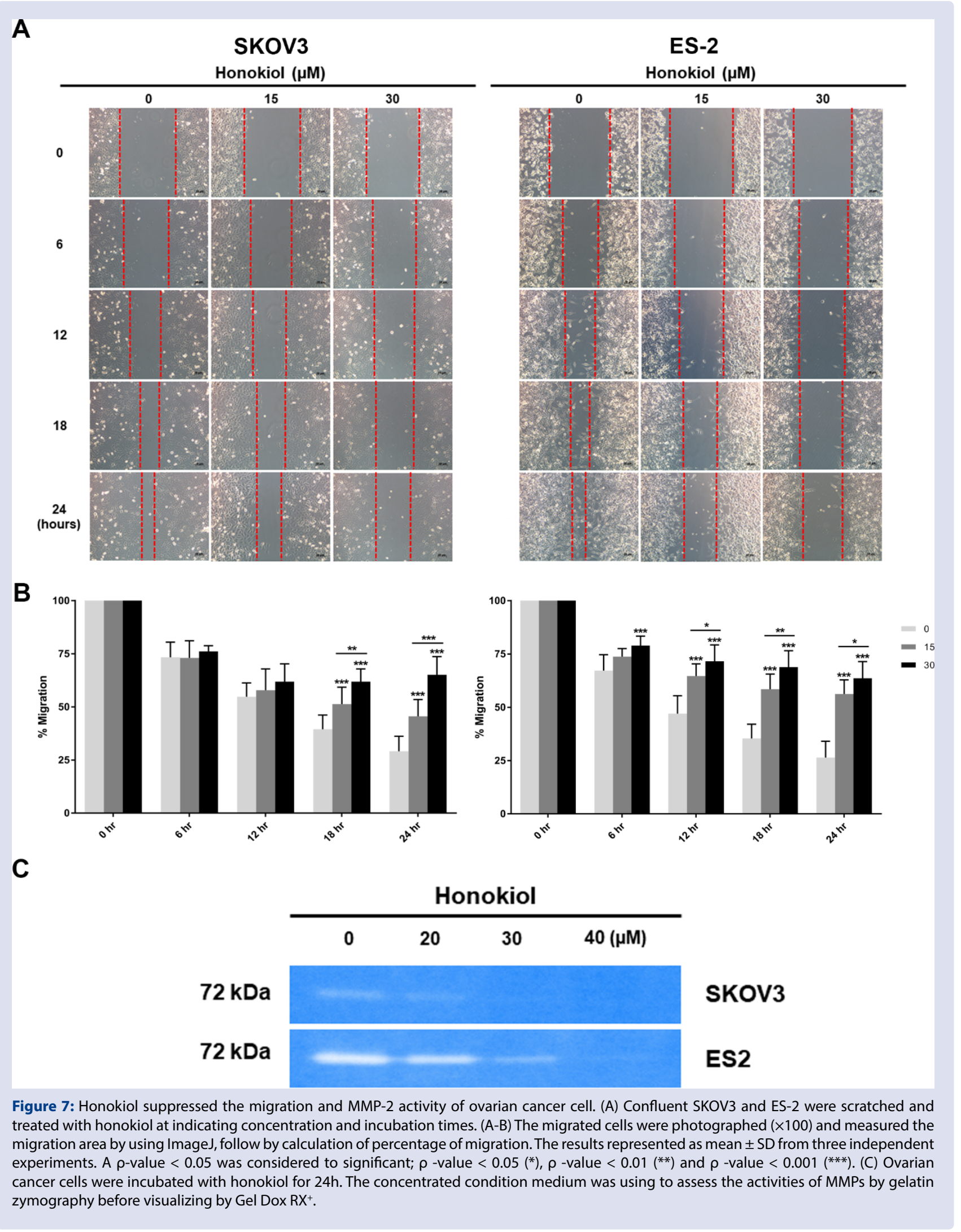




\section{REFERENCES}

1. Jayson GC, Kohn EC, Kitchener HC, Ledermann JA. Ovarian cancer. The Lancet. 2014;384(9951):1376-88

2. Bast RC, Hennessy B, Mills GB. The biology of ovarian cancer: new opportunities for translation. Nature Reviews Cancer. 2009;9(6):415-28.

3. National Cancer Institute. SEER Cancer Statistics Factsheets: Ovarian Cancer Bethesda, MD: National Cancer Institute; 2018 [Available from: https://seer.cancer. gov/statfacts/html/ovary.html].

4. Mills K, Fuh K. Recent Advances in Understanding, Diagnosing, and Treating Ovarian Cancer [version 1; referees: 3 approved]. F1000Research. 2017;6(84).

5. Lee Y-J, Lee YM, Lee C-K, Jung JK, Han SB, Hong JT. Therapeutic applications of compounds in the Magnolia family. Pharmacology \& Therapeutics. 2011;130(2):15776.

6. Hsu YF, Lee TS, Lin SY, Hsu SP, Juan SH, Hsu YH, et al. Involvement of Ras/Raf-1/ ERK actions in the magnolol-induced upregulation of p21 and cell-cycle arrest in colon cancer cells. Molecular Carcinogenesis. 2007;46(4):275-83.

7. Lin SY, Chang YT, Liu JD, Yu CH, Ho YS, Lee YH, et al. Molecular mechanisms of apoptosis induced by magnolol in colon and liver cancer cells. Molecular Carcinogenesis. 2001;32(2):73-83.

8. Battle TE, Arbiser J, Frank DA. The natural product honokiol induces caspasedependent apoptosis in B-cell chronic lymphocytic leukemia (B-CLL) cells. Blood. 2005;106(2):690-7.

9. Yang S-E, Hsieh M-T, Tsai T-H, Hsu S-L. Down-modulation of Bcl-X L, release of cytochrome $\mathrm{c}$ and sequential activation of caspases during honokiol-induced apoptosis in human squamous lung cancer $\mathrm{CH} 27$ cells. Biochemical Pharmacology. 2002;63(9):1641-51.

10. Chuang T-C, Hsu S-C, Cheng Y-T, Shao W-S, Wu K, Fang G-S, et al. Magnolol downregulates HER2 gene expression, leading to inhibition of HER2-mediated metastatic potential in ovarian cancer cells. Cancer Letters. 2011;311(1):11-9.

11. Lee YJ, Lee YM, Lee CK, Jung JK, Han SB, Hong JT. Therapeutic applications of compounds in the Magnolia family. Pharmacol Ther. 2011;130(2):157-76.
12. Li Z, Liu Y, Zhao X, Pan X, Yin R, Huang C, et al. Honokiol, a natural therapeutic candidate, induces apoptosis and inhibits angiogenesis of ovarian tumor cells. European Journal of Obstetrics \& Gynecology and Reproductive Biology. 2008;140(1):95-102.

13. Ferlay J, Soerjomataram I, Dikshit R, Eser S, Mathers C, Rebelo M, et al. Cancer incidence and mortality worldwide: sources, methods and major patterns in GLOBOCAN 2012. International Journal of Cancer. 2015;136(5):E359-86.

14. du Bois A, Reuss A, Pujade-Lauraine E, Harter P, Ray-Coquard I, Pfisterer J. Role of surgical outcome as prognostic factor in advanced epithelial ovarian cancer: a combined exploratory analysis of 3 prospectively randomized phase 3 multicenter trials: by the Arbeitsgemeinschaft Gynaekologische Onkologie Studiengruppe Ovarialkarzinom (AGO-OVAR) and the Groupe d'Investigateurs Nationaux Pour les Etudes des Cancers de l'Ovaire (GINECO). Cancer. 2009;115(6):1234-44.

15. Yang S-E, Hsieh M-T, Tsai T-H, Hsu S-L. Effector mechanism of magnolol-induced apoptosis in human lung squamous carcinoma $\mathrm{CH} 27$ cells. British Journal of Pharmacology. 2003;138(1):193-201

16. Li Z, Liu Y, Zhao X, Pan X, Yin R, Huang C, et al. Honokiol, a natural therapeutic candidate, induces apoptosis and inhibits angiogenesis of ovarian tumor cells. European Journal of Obstetrics, Gynecology, and Reproductive Biology. 2008;140(1):95-102.

17. Xu HL, Tang W, Du GH, Kokudo N. Targeting apoptosis pathways in cancer with magnolol and honokiol, bioactive constituents of the bark of Magnolia officinalis. Drug Discoveries \& Therapeutics. 2011;5(5):202-10.

18. Guan X. Cancer metastases: challenges and opportunities. Acta pharmaceutica Sinica B. $2015 ; 5(5): 402-18$

19. Jeong JJ, Lee JH, Chang KC, Kim HJ. Honokiol exerts an anticancer effect in T98G human glioblastoma cells through the induction of apoptosis and the regulation of adhesion molecules. Int J Oncol. 2012;41(4):1358-64.

20. Liu Y, Cao W, Zhang B, Liu YQ, Wang ZY, Wu YP, et al. The natural compound magnolol inhibits invasion and exhibits potential in human breast cancer therapy. Sci Rep. 2013;3:3098.

21. Zhang FH, Ren HY, Shen JX, Zhang XY, Ye HM, Shen DY. Magnolol suppresses the proliferation and invasion of cholangiocarcinoma cells via inhibiting the NFkappaB signaling pathway. Biomedicine \& Pharmacotherapy $=$ Biomedecine \& Pharmacotherapie. 2017;94:474-80.

\section{GRAPHICAL ABSTRACT}

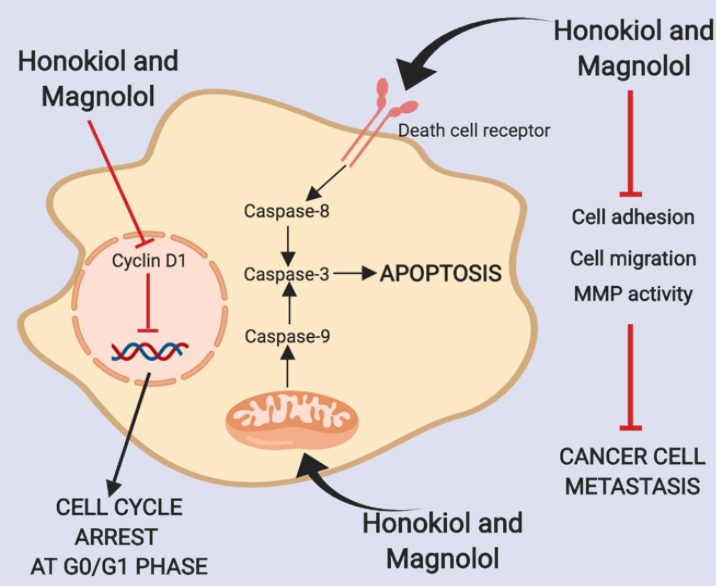

\section{SUMMARY}

The magnolia-derived compounds, honokiol and magnolol exhibited the antitumour activities on ovarian cancer. Including inhibition of cell proliferation mediated by downregulation of cyclin D1 and induction of cell apoptosis through either death receptor or mitochondria pathways. Moreover, these compounds inhibited cell adhesion, migration and MMP activities indicated that the suppression of cancer cell metastasis.

\section{ABOUT AUTHORS}

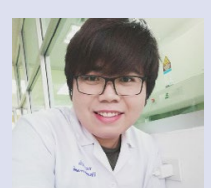

Worawat Songjang completed his Ph.D. degree in Biomedical Sciences program from Naresuan University, Phitsanulok, Thailand. Currently, he is a researcher at faculty of Allied Health Sciences, Naresuan University. His areas of interests are the cancer biology and cancer immunotherapy. 
Arunya Jiraviriyakul is assistant professor and researcher at Naresuan university since 2003. She made her Ph.D in Molecular biology and biotechnology from The university of Sheffield, UK. She has also followed the postdoctoral fellowship at Kumamoto University, Japan. Her major research area focus is on studying cancer biology and cancer immunotherapy.

Cite this article: Songjang W, Jiraviriyakul A. Honokiol and magnolol induce apoptosis and cell cycle arrest in human ovarian cancer cells. Pharmacog J. 2019;11(5):1114-23. 